\title{
Development of a block system for controlling the main parameters of the seed separation process based on air-gravity machines
}

\author{
Stanislav Gerasimenko ${ }^{1 *}$, Artak Adamyn ${ }^{1}$, Dmitriy Podlesniy ${ }^{2}$, and Valentin Mishin ${ }^{3}$ \\ ${ }^{1}$ Federal Scientific Agro-Engineering Center VIM, 1 Institutsky proezd, 5, Moscow, 109428, Russia \\ ${ }^{2}$ Don state technical university, Gagarin Square, 1, Rostov-on-Don, 344000, Russia \\ ${ }^{3}$ Rostov State Transport University, Rostovskogo Strelkovogo Polka Narodnogo Opolcheniya Square, \\ 2, Rostov-on-Don, 344038, Russia
}

\begin{abstract}
The paper presents the development of a program for controlling the main parameters of the separation process in the industrial automation instrumental complex CODESYS V3. Also the visualization of the control panel was developed. Based on this, a control unit was assembled with the presented version of the software visualization for controlling the main parameters of the air-gravity machine.
\end{abstract}

\section{Introduction}

Post-harvest processing of grain and seeds is one of the most labor-intensive branches of agricultural production. Automation of technological processes in grain cleaning equipment leads to a decrease in the labor costs of the operating staff. Under the influence of numerous disturbances that affect the efficiency of grain cleaning machines, the operating staff in the manual control mode are not able to respond in a timely manner and change the settings of the main parameters. It leads to a decrease in the productivity and quality of the cleaned material [1-3].

The main complicating factor in choosing the most effective areas of automation in the field of air-gravity machines is a little generalized experience in the development, practical implementation and application of automation devices for monitoring and controlling machine parameters.

\section{Materials and methods}

Any grain cleaning machine works with variable loading of grain material. The moisture and purity of the processed material are influenced on it, as well as the physical and mechanical properties of the seeds. In this regard, it can be seen that in order to improve the quality of cleaning, a constant adjustment of the position of the bunker gate is required for optimal material supply.

\footnotetext{
*Corresponding author: tomasss1086@mail.ru
} 
A program was developed in the industrial automation tool complex CODESYS V3. It is responsible for the control and management of the main processes taking place in the airgravity grain cleaning machine (Fig. 1) [4].

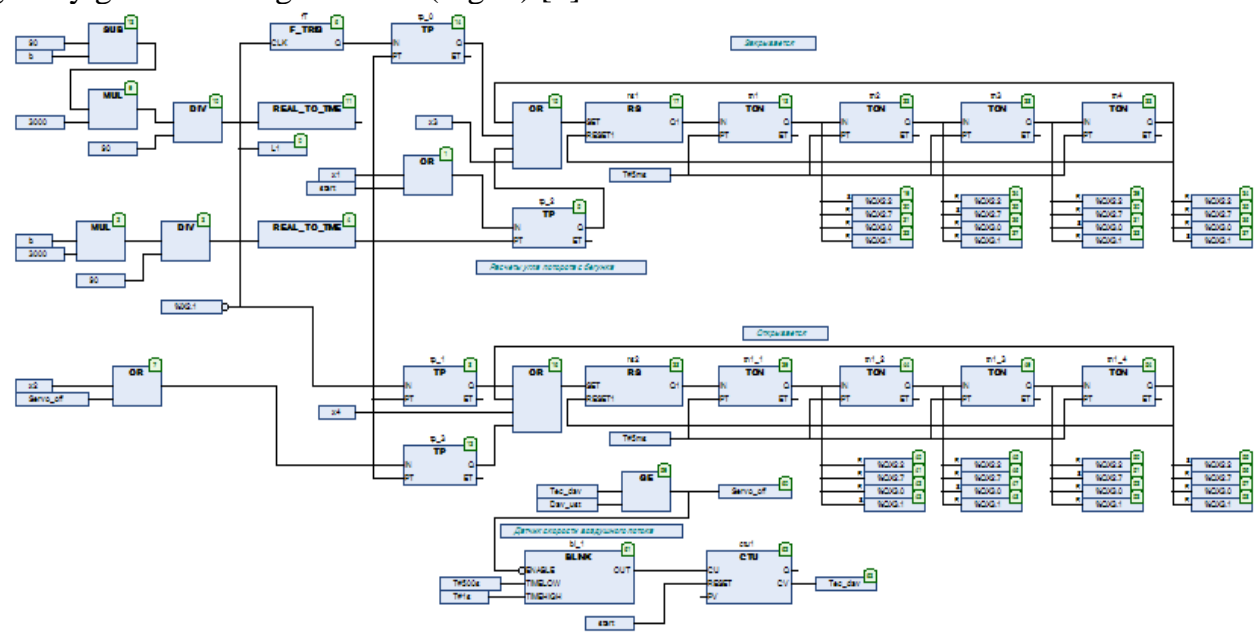

Fig. 1. Program for the control and monitoring of the main parameters in the cleaning seeds process.

Depending on the signal received from the laser sensor «Laser», the control device decides to open or close the shutter of the grain supply valve on the bunker.

If the control device receives a signal from the laser sensor, which means that the grain supply bunker is full, the program automatically closes the shutter or opens the grain supply to a predetermined "X» number of degrees. After the signal from the laser sensor stops coming, which means that the bunker is empty, the program automatically returns the shutter to the initial position «X».

Also, it is possible to manually control the rotation of the stepper motor which installed on the material feed bunker. For this purpose, buttons «Open / Close the Valve» are created on the visualization panel, they will open and close the valve at the set angle «x». Buttons «Regulation to open / close the Valve» rotate the valve flap in the forward and backward direction with a single step the opening angle of the shutter in 1 degree [5].

In addition to the above operations, the program includes the operation of air speed sensors in the pneumosorting channel, which controls the air speed in the channels. Reducing the speed in the channels signals the operator about the dustiness of the bags using the "Clean the filter» indicator. Then the signal to turn on the auger «Turn on the auger» is received. Depending on the material and its contamination, the auger is switched on for a certain period of time. This function of the program is due to the fact that constant operation of the auger is not required, as well as in order to save energy and reduce the noise of the machine as a whole. After the auger has unloaded the light impurity, it turns off. "AM violet lamp» the ultraviolet lamp works constantly to disinfect the material, it turns off only after the end of the machine or in manual forced mode [6,7].

\subsection{Process visualization}

Visualization of the control panel in the CODESYS V3 industrial automation software application was developed To enable convenient and remote control of the grain cleaning machine processes $[8,9]$. With its help, it is possible to display control objects on a wireless screen, and also, it becomes possible to control these processes remotely via the web interface, if there is a connected (wired or wireless) Internet. 


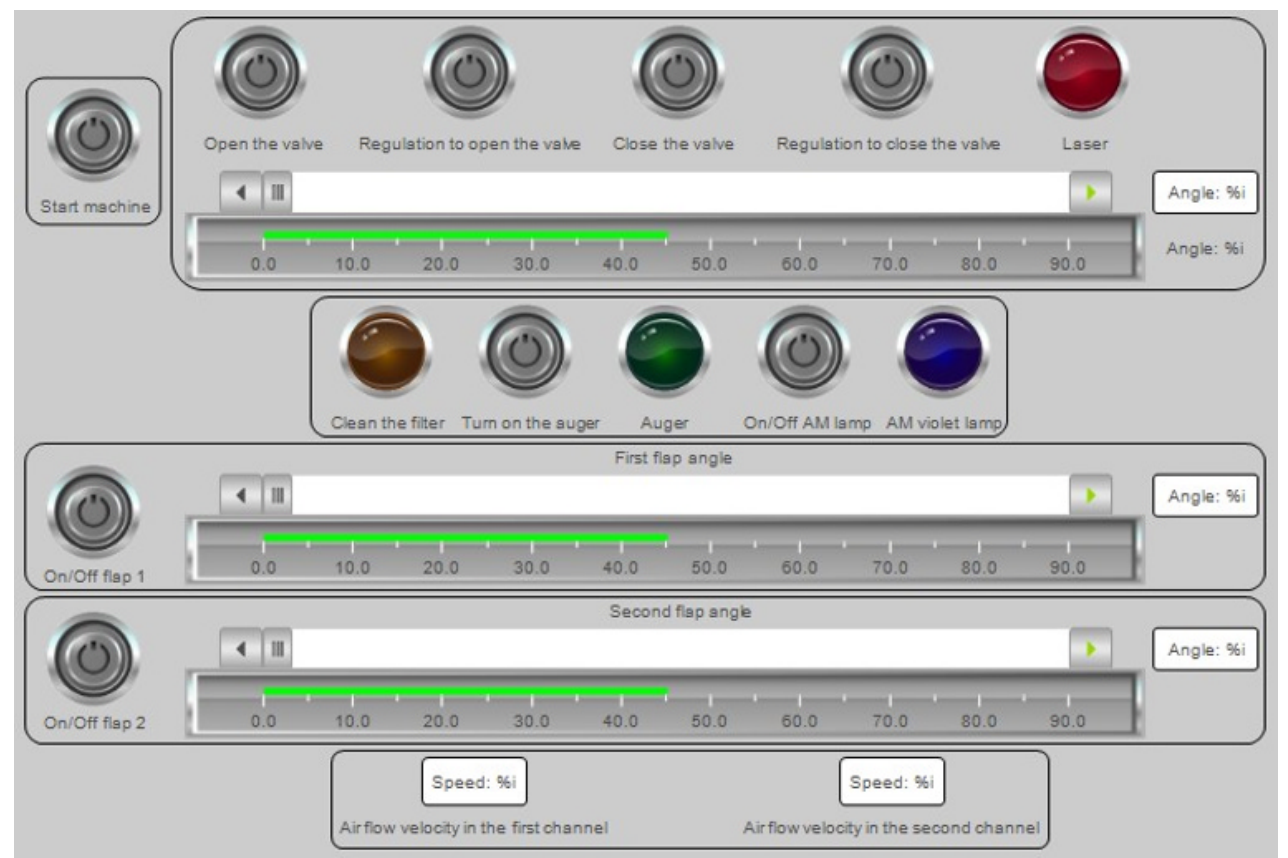

Fig. 2. Graphical representation of the control panel (web interface).

Figure 2 contains the controls:

- «Start machine» - launching the machine;

- «Open the valve» - opening the shutter to the set number of degrees;

- «Regulation to open the valve» - increasing the opening angle of the shutter in manual control;

- «Close the valve» - return of the damper to its original position or complete closing of the shutter;

- «Regulation to close» - decreasing the opening angle of the shutter in manual control;

- «Laser» - laser sensor indicator;

- Manual switch «Regulator» - allows the operator to set the gate opening / closing angle with an accuracy of 1 degree (0-90 degrees).

- «Clean the filter» - filter dust indicator;

- «Turn on the auger» - turning on the auger in manual mode;

-«Auger» - auger operation indicator;

-«On/off AM lamp» - turning the UV lamp on and off;

-«AM violet lamp» - UV lamp operation indicator;

-«On/off flap 1» - manual opening of shutter 1;

-Manual switch «Regulator $1 »$;

- «On / off flap 2» manual opening of the shutter 2;

-Manual switch «Regulator 2»;

At the bottom of the screen, digital readings of the air speed sensors of the first and second channels are displayed. 
Table 1. Input variables of the control program

\begin{tabular}{|c|c|}
\hline Program text & Comments \\
\hline \multicolumn{2}{|l|}{ PROGRAM PLC_PRG } \\
\hline \multicolumn{2}{|l|}{ VAR } \\
\hline rs1: RS; & discharge \\
\hline tn1: TON; & turn-on delay timer \\
\hline \multicolumn{2}{|l|}{ tn2: TON; } \\
\hline \multicolumn{2}{|l|}{ tn3: TON; } \\
\hline \multicolumn{2}{|l|}{ tn4: TON; } \\
\hline tp_0: TP; & timer (trigger) \\
\hline \multicolumn{2}{|l|}{ tp_1: TP; } \\
\hline fT: F_TRIG; & trailing edge \\
\hline \multicolumn{2}{|l|}{ rs2: RS; } \\
\hline \multicolumn{2}{|l|}{ tn1_1: TON; } \\
\hline \multicolumn{2}{|l|}{ tn1_2: TON; } \\
\hline \multicolumn{2}{|l|}{ tn1_3: TON; } \\
\hline \multicolumn{2}{|l|}{ tn1_4: TON; } \\
\hline x1: BOOL; & manual start of the engine in the forward direction by "x" degrees \\
\hline x2: BOOL; & manual start of the engine in the reverse direction by "x" degrees \\
\hline x3: BOOL; & control of the engine position in the forward direction \\
\hline x4: BOOL; & control of the engine position in the reverse direction \\
\hline L1: BOOL; & variable, displays the state of the laser sensor in the visualization \\
\hline Dav_ust: REAL :=200; & set pressure \\
\hline Tec_dav: REAL :=0; & current pressure \\
\hline Servo_off: BOOL; & engine shutdown \\
\hline ctu1: CTU; & incremental counter \\
\hline bl_1: BLINK; & pulse generator \\
\hline start: BOOL; & starting the machine after replacing the filter \\
\hline rev: BOOL; & fan reverse \\
\hline b: REAL; & slider \\
\hline \multicolumn{2}{|l|}{ tp_2: TP; } \\
\hline \multicolumn{2}{|l|}{ tp_3: TP; } \\
\hline b1: REAL:=45; & 1st flap slider (angle) \\
\hline b2: REAL:=60; & 2nd flap slider (angle) \\
\hline s1: REAL:=15; & speed in the first stream \\
\hline s2: REAL:=20; & speed in the second stream \\
\hline f1: BOOL; & on / off shutter 1 \\
\hline f2: BOOL; & on / off shutter 2 \\
\hline AM: BOOL; & on / off UV lamp \\
\hline AGR: BOOL; & on / off auger \\
\hline
\end{tabular}

After the development of the software, a block-control system was assembled to automatically control the parameters of the seed cleaning process (Figure 3).

The process control unit (Fig. 3) includes:

- control device - Raspberry Pi 3; 
- breadboard, on which power and ground for the infrared sensor and the stepper motor were divorced;

- driver for stepping engine control on the feed bunker.

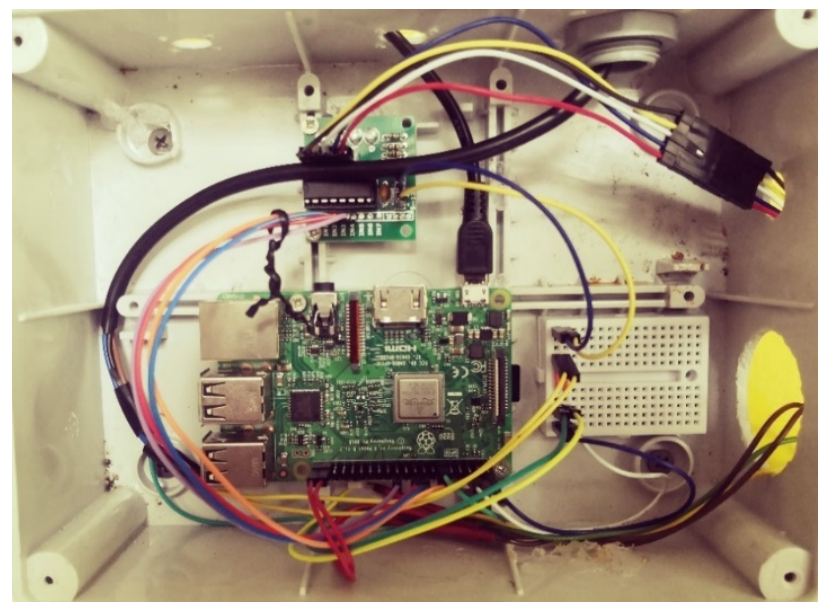

Fig. 3. The control unit for the processes of the program module.

The infrared detection sensor (IS) E18-D80NK and a stepping engine (SE) are installed on the bunker of the cleaning machine.

IS consists of an infrared emitter and a receiver, and it operates at a distance of up to 80 $\mathrm{cm}$. It is used to measure the grain level in the bunker relative to the maximum set value (upper point of the bunker), if this mark is exceeded, a signal is sent to the control device (hereinafter $\mathrm{CD}$ ) and SE closes the valve for supplying the material to be cleaned.

$\mathrm{SE}$ is distinguished by its small size and comparatively high torque. One is intended to open / close a valve for feeding grain, and the other two are intended to adjust the air flow rate in the air channel. Thus, it becomes possible, with an accuracy of one degree, to raise / lower the shutter of the grain supply bunker, thereby constantly controlling the volume and speed of material feeding, as well as setting the desired opening / closing angle of the shutters in the pneumatic channel.

An air speed sensor is installed in the lower parts of the air channel sections, which measures the difference in speed values in the pneumatic channel. With an increase in the level of filling the filter with dust and impurities, the pressure increases and the speed in the pneumatic channel decreases. If the filter is not cleaned in time, the degree of contamination of the cleaned material will increase over time, which will lead to the need to re-purify the same material. Automatic feed cut-off eliminates this problem.

All these devices based on wired connections are connected to the control unit, which receives, processes and at a certain moment sends signals to each of the devices.

\section{Conclusions}

1. A program and technical system for the control and monitoring of the parameters of the seed separation process was developed on the basis of the existing laboratory facilities for cleaning seeds.

2. The visualization of the control panel of the air-gravity grain cleaning machine was developed.

3. The block-control system of the air-gravity machine for cleaning bulk grain mixtures and seeds has been developed and assembled. 


\section{References}

1. M.N. Moskovskiy, A.A. Boyko, Engineering Bulletin of Don. № 1 http:/www.ivdon.ru/magazine/archive/n1y2012/669, (2014).

2. V. Khamyev, A. Gulyev, G. Adamyan, A. Boiko, M.B. Quang, MATEC Web Conf. 32905009 (2020).

3. M.N. Moskovskiy, Intensification of the process of separation of grain seeds in grain cleaning units. - Rostov-on-Don, (2005).

4. S. Gerasimenko, A. Adamyan, M. Moskovsky, M.B. Quang, MATEC Web Conf. 329, 05008 (2020).

5. S.I. Baskakov, M .: Higher school, 462, (2000).

6. A.A. Shalyto Logical control. SPb .: Science, 780, (2000).

7. Yu.G. Karpov Theory of automata. SPb .: Piter, 224, (2002).

8. Yu.P. Adler, E.V. Morkova, Yu.V. Granovsky, M .; Science 280, (1976).

9. StatSoft STATISTICA 10, Russian Portable, R4 2011. 